DOI 10.37882/2223-2974.2020.10.34

\title{
ОЦЕНКА НАДЕЖНОСТИ СИСТЕМЫ ВНУТРЕННЕГО КОНТРОЛЯ ДЕБИТОРСКОЙ И КРЕДИТОРСКОЙ ЗАДОЛЖЕННОСТИ ОАО «РЖД»
}

\section{ASSESSMENT OF THE RELIABILITY OF THE INTERNAL CONTROL SYSTEM OF ACCOUNTANTS AND CREDITS DEBT OJSC «RUSSIAN RAILWAYS»}

\section{T. Tarasova}

O. Tarasova

Summary: Management of the organization's settlements and control over them is one of the key elements of the general policy of the enterprise, and includes, in addition to the management and control of the level of debt, also the determination of the terms of sale, the development of basic rules and payment policy and cash flow to ensure economic efficiency of activities ...

The purpose of this article is to assess the reliability of the internal control system (ICS) of receivables and payables, as well as to develop the necessary additions to the existing ICS tools at railway transport enterprises.

Method or methodology of the work: The methodological basis of this article is the works of domestic and foreign scientists, as well as regulatory documents on the theory and practice of the functioning of the internal control system and risk assessment at enterprises. In the course of the research, various mathematical methods were used, as well as methods of analysis, analogy, comparison, modeling and others. An integrated and systematic approach was used to summarize the results and draw conclusions.

As a result of the SWOT analysis of the ICS of receivables and payables at Russian Railways, it was concluded that the control procedures at Russian Railways were developed in detail and contain a sufficient amount of information and a clear sequence of actions. The strengths of Russian Railways are such positions as: leadership in the transport services market of the Russian Federation and a sufficiently developed IT infrastructure that allows connecting cities, structures, departments. The weakest aspect of the activity of the ICS of JSC «Russian Railways» is the nature of the activity and the current state of the railways in the Russian Federation, which does not allow using international experience to the full.

Scope of the results: This material can be used not only within the framework of transport enterprises, but also with some changes for the necessary structures, can be used by organizations of other industries in charge of, for example, cargo transportation, logistics, construction work.

Keywords: accounts receivable, accounts payable, internal control, internal audit, internal control system.

\author{
Тарасова Татьяна Михайловна \\ К.э.н., дочент, Самарский государственный \\ университет путей сообщения \\ tarasova2004@inbox.ru \\ Тарасова Ольга Валерьевна \\ старший преподаватель, Самарский \\ государственный университет путей сообщения \\ tarasova-olga62@inbox.ru
}

Аннотация: Управление расчётами организации и контроль над ними являются один из ключевых элементов общей политики предприятия, и включает в себя помимо самого управления и контроля за уровнем задолженности, также и определение условий продаж, разработку основных правил и платёжной политики и движения денежных средств для обеспечения экономической эффективности деятельности.

Целью данной статьи является оценка надежности системы внутреннего контроля (СВК) дебиторской и кредиторской задолженности, а также разработка необходимых дополнений к имеющемуся инструментарию СВК на предприятиях железнодорожного транспорта.

Метод или методология проведения работы: Методической основой данной статьи являются труды отечественных и зарубежных ученых, а также нормативные документы по вопросам теории и практики функционирования системы внутреннего контроля и оценки рисков на предприятиях. В процессе исследования применялись как различные математические методы, так и методы анализа, аналогии, сравнения, моделирования и другие. Комплексный и системный подходы использовались при обобщении результатов и формировании выводов.

B результате SWOT-анализа CBK дебиторской и кредиторской задолженности на ОАО «РЖД» пришли к выводам, что контрольные процедуры в ОАО «РЖД» разработаны подробно и содержат в себе достаточный объем информации и четкую последовательность действий. Сильными сторонами ОАО «РЖД» являются такие позиции, как: лидерство на рынке транспортных услуг Российской Федерации и достаточно развитая ІТ-инфраструктура, позволяющая связывать города, структуры, отделы. Самой слабой стороной деятельности СВК ОАО «РЖД» является характер деятельности и текущее состояние железных дорог в Российской Федерации, который не позволяет использовать международный опыт в полной мере.

Область применения результатов: Данный материал может быть использован не только в рамках транспортных предприятий, но также с некоторыми изменениями под необходимые структуры, может быть использован организациями других отраслей, курирующих, например, грузоперевозки, логистику, строительные работы.

Ключевые слова: дебиторская задолженность, кредиторская задолженность, внутренний контроль, внутренний аудит, система внутреннего контроля. 


\section{Введение}

$\mathrm{C}$ истема внутреннего контроля ОАО «РЖД» - совокупность методов и процедур (средств контроля) с помощью которых субъект контроля (персонал организации) оценивает риски не достижения поставленных целей (установленных значений объектов контроля).

Хочется отметить, что ОАО «РЖД» - не рискориентированная организация, поэтому основная задача СВК ОАО «РЖД» в целом - это свести к минимуму возможные риски для успешной работы и функционирования компании в современных условиях.

Преимуществами внедрения СВК в работу ОАО «РЖД» являются следующие пункты:

- повышение качества отчётности;

- повышение эффективности бизнес-процессов;

- повышение качества управленческих решений;

- снижение объема замечаний со стороны аудиторов;

- снижение стоимости аудита;

- улучшение имиджа компании, В том числе для инвесторов, партнеров и потребителей;

- установка дополнительного контроля над дочерними компаниями.

Целью данной статьи является оценка надежности СВК дебиторской и кредиторской задолженности, а также разработка необходимых дополнений к имеющемуся инструментарию СВК на предприятиях железнодорожного транспорта.

\section{Метод или методология проведения работы}

Методической основой данной статьи являются труды отечественных и зарубежных ученых, а также нормативные документы по вопросам теории и практики функционирования системы внутреннего контроля и оценки рисков на предприятиях. В процессе исследования применялись как различные математические методы, так и методы анализа, аналогии, сравнения, моделирования и другие. Комплексный и системный подходы использовались при обобщении результатов и формировании выводов.

\section{Результаты и обсужмение}

Далее рассмотрим вопрос формирования контрольных процедур при учете и отражении дебиторской и кредиторской задолженности. Согласно документу Министерства финансов Российской Федерации №П3-11\2013 «Организация и осуществление экономическим субъектом внутреннего контроля совершаемых фактов хозяйственной жизни, ведения бухгалтерского учёта и составления бухгалтерской (финансовой) отчётности», хозяйствующий субъект может применять определённые контрольные процедуры.

Исполнителем контрольных процедур является Общий центр обслуживания (регион).

Контрольные процедуры в ОАО «РЖД» разработаны подробно и содержат в себе достаточный объем информации и, более того, четкую последовательность действий. Также можно отметить, что перечень контрольных процедур затрагивают еще и такую важную часть контрольной деятельности, как организация бухгалтерского документооборота.

Проанализируем СВК дебиторской и кредиторской задолженности на рассматриваемых предприятиях, и представим результаты анализа в матрице SWOT в Taблице 1.

Характеристики в данной матрице SWOT в Таблице 1 не являются исчерпывающими. Необходимо учитывать ещё следующее: высокая репутация компании ОАО «РЖД» и стабильность в выполнении своей работы (сильная сторона), возможный отток квалифицированных кадров (угроза), а также невозможность сразу и полностью управлять многими процессами (слабая сторона).

На основании SWOT-анализа, приведенного в Таблице 1, можно выделить с помощью экспертных оценок наиболее значимые характеристики, оказывающие влияние на развитие СВК в ОАО «РЖД». В Таблице в 2 представим рейтинговую шкалу оценки степени влияния Strengths (Сильных сторон) СВК на эффективность её деятельности на рынке.

Итак, в соответствии со Шкалой оценки, приведенной в Таблице 2, оценим сильные стороны деятельности СВК. Результаты представим в Таблице 3.

Таким образом, в текущей ситуации, ключевыми Strengths (Сильными сторонами) являются такие позиции, как: лидерство на рынке транспортных услуг Российской Федерации и достаточно развитая ITинфраструктура, позволяющая связывать города, структуры, отделы.

По аналогии co Strengths (Сильными сторонами), представим данные по Weaknesses (Слабым сторонам) в Таблицах 4 и 5.

Далее представим Таблицу экспертных оценок Weaknesses (Слабых сторон) деятельности СВК ОАО «РЖД».

Таким образом, самой существенной Weaknesses 
Таблица 1.

SWOT-анализ CBK дебиторской и кредиторской задолженности на ОАО «РЖД»

\begin{tabular}{|c|c|}
\hline Strengths (Сильные стороны), $S_{i}$ & Weaknesses (Слабые стороны), W \\
\hline 1 & 2 \\
\hline $\begin{array}{l}S_{1} \text { - лидерство на рынке транспортных услуг Российской Федерации; } \\
S_{2} \text { - ведущие позиции в сфере транспорта на мировом уровне; } \\
S_{3} \text { - высокий технологический уровень разработок, постоянное отслежива- } \\
\text { ние новинок, внедрение свежих продуктов в деятельность компании; } \\
S_{4} \text { - наличие кадров с высокой квалификацией, а также возможность обу- } \\
\text { чать персонал корпоративной культуре, специфике работы; } \\
S_{5} \text { - достаточно развитая IT-инфраструктура, позволяющая связывать горо- } \\
\text { да, структуры, отделы; } \\
S_{6} \text { - мониторинг и анализ собственной деятельности, поиск ошибок и спосо- } \\
\text { бов их минимизации и устранения; } \\
S_{7} \text { - чёткое следование принципам работе компании, и в то же время - от- } \\
\text { крытость к изменениям, апробациям, новшествам }\end{array}$ & $\begin{array}{l}\text { W - не все внедряемые позиции оказываются полезными для деятельности } \\
\text { компании; } \\
\text { W } \text { - дорогостоящее научное и инженерное оборудование, невозможность } \\
\text { внедрить идеи сразу же, т.к. может быть не готова база для апробации; } \\
\text { W - характер деятельности и текущее состояние железных дорог в Россий- } \\
\text { ской Федерации не позволяет использовать международный опыт в полной } \\
\text { мере; } \\
\text { W - некоторые позиции в деятельности недостаточно отработаны на прак- } \\
\text { тике, и потребуется еще время, чтобы разработать наиболее оптимальный } \\
\text { способ осуществлять работу; } \\
\text { W - большой размер задолженности оказывает прямое воздействие на фи- } \\
\text { нансовую структуру всей организации }\end{array}$ \\
\hline Opportunities (Возможности), $0_{i}$ & Threats (Угрозы), $\mathrm{T}_{\mathrm{i}}$ \\
\hline 3 & 4 \\
\hline $\begin{array}{l}\text { 0 - возможность выступать на международной арене, предлагая свои раз- } \\
\text { работки и пользуясь опытом других стран; } \\
\text { 0 - возможность повышать свой международный рейтинг; } \\
\text { 0 - развитие внутренней информационной и отчётной базы; } \\
\text { 0 - модернизация транспортного комплекса с учетом потребностей и воз- } \\
\text { можностей компании, совершенствование транспортной системы страны }\end{array}$ & $\begin{array}{l}\mathrm{T}_{1} \text { - любая СВК может быть недостаточно разработана или не иметь в себе } \\
\text { плана действий в нештатной ситуации; } \\
\mathrm{T}_{2} \text { - внутренние ошибки, злоупотребления, преступления, коррупция; } \\
\mathrm{T}_{3} \text { - рост конкуренции на мировом рынке, возникает риск отставания от об- } \\
\text { щих тенденций, что влечет за собой снижение позиций; } \\
\mathrm{T}_{4} \text { - невозможность внедрения новшеств из-за недостаточности ресурсов и } \\
\text { из-за разной освоенности территории страны; } \\
\mathrm{T}_{5} \text { - финансово-экономический кризис }\end{array}$ \\
\hline
\end{tabular}

Таблица 2.

Шкала оценки Strengths (Сильных сторон) деятельности СВК в ОАО «РЖД», баллы

\begin{tabular}{|c|c|l|}
\hline № п/п & Оценка & \multicolumn{1}{c|}{ Пояснение } \\
\hline 1 & 2 & \\
\hline 1. & 5 & Ярко выраженное преимущество \\
\hline 2. & $3-4$ & Потенциал сильной стороны на достаточном уровне, высокий \\
\hline 3. & $1-2$ & Есть вероятность, что сильная сторона развита на допустимом уровне \\
\hline
\end{tabular}

Таблица 3.

Экспертная оценка Strengths (Сильных сторон) деятельности СВК ОАО «РЖД», баллы

\begin{tabular}{|c|c|c|}
\hline № $\Pi / \Pi$ & Сильные стороны деятельности СВК ОАО «РЖД» & Оценка в баллах \\
\hline 1 & 2 & 3 \\
\hline 1. & $S_{1}$ - лидерство на рынке транспортных услуг Российской Федерации & 5 \\
\hline 2. & $S_{2}$ - ведущие позиции в сфере транспорта на мировом уровне & 4 \\
\hline 3. & $\begin{array}{l}\mathrm{S}_{3} \text { - высокий технологический уровень разработок, постоянное отслеживание новинок, внедрение свежих продуктов в дея- } \\
\text { тельность компании }\end{array}$ & 4 \\
\hline 4. & $\begin{array}{l}\mathrm{S}_{4} \text { - наличие кадров с высокой квалификацией, а также возможность обучать персонал корпоративной культуре, специфике } \\
\text { работы }\end{array}$ & 4 \\
\hline 5. & $\mathrm{~S}_{5}$ - достаточно развитая IT-инфраструктура, позволяющая связывать города, структуры, отделы & 5 \\
\hline 6. & $\mathrm{~S}_{6}$ - мониторинг и анализ собственной деятельности, поиск ошибок и способов их минимизации и устранения & 4 \\
\hline 7. & $\mathrm{~S}_{7}$ - чёткое следование принципам работе компании, и в то же время - открытость к изменениям, апробациям, новшествам & 4 \\
\hline
\end{tabular}


(Слабой стороной) деятельности СВК ОАО «РЖД» является характер деятельности и текущее состояние железных дорог в Российской Федерации, который не позво- ляет использовать международный опыт в полной мере. В свою очередь это приводит к отставанию всей железнодорожной отрасли Российской Федерации в общем

Таблица 4.

Рейтинговая шкала для оценки степени влияния Weaknesses (Слабых сторон) СВК ОАО «РЖД» на его финансовое положение

\begin{tabular}{|c|c|l|}
\hline$№$ п/п & Оценка в баллах & \multicolumn{1}{c|}{ Пояснение } \\
\hline 1 & 2 & \\
\hline 1. & $-2-1$ & Достаточная низкая позиция Weaknesses (Слабых сторон) \\
\hline 2. & $-4-3$ & Низкая позиция Weaknesses (Слабой стороны) \\
\hline 3. & -5 & Ярко выраженные Weaknesses (Слабые стороны) \\
\hline
\end{tabular}

Экспертная оценка Weaknesses (Слабых сторон) деятельности СВК ОАО «РЖД», баллы

\begin{tabular}{|c|c|c|}
\hline № $\Pi / п$ & Слабые стороны деятельности СВК ОАО «РЖД» & Оценка в баллах \\
\hline 1 & 2 & 3 \\
\hline 1. & 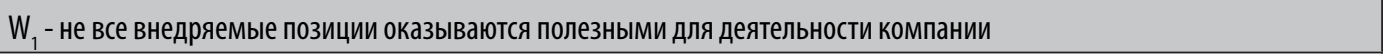 & -2 \\
\hline 2. & $\begin{array}{l}W_{2} \text { - дорогостоящее научное и инженерное оборудование, невозможность внедрить идеи сразу же, т.к. может быть не } \\
\text { готова база для апробации }\end{array}$ & -3 \\
\hline 3. & $\begin{array}{l}\text { W } \text { - характер деятельности и текущее состояние железных дорог в Российской Федерации не позволяет использовать } \\
\text { международный опыт в полной мере }\end{array}$ & -4 \\
\hline 4. & $\begin{array}{l}\mathrm{W}_{4} \text { - некоторые позиции в деятельности недостаточно отработаны на практике, и потребуется еще время, чтобы разрабо- } \\
\text { тать наиболее оптимальный способ осуществлять работу }\end{array}$ & -2 \\
\hline 5. & $\mathrm{~W}_{5}$ - большой размер задолженности оказывает прямое воздействие на финансовую структуру всей организации & -3 \\
\hline
\end{tabular}

Шкала оценки степени влияния Орportunities (Возможностей) и Threats (Угроз) СВК ОАО «РЖД»

Таблица 6. на финансовое положение

\begin{tabular}{|c|c|c|}
\hline № $n / п$ & Значение & Степень влияния \\
\hline 1 & 2 & 3 \\
\hline 1. & $0,71-1,0$ & Сильная \\
\hline 2. & $0,36-0,70$ & Средняя \\
\hline 3. & $0,00-0,35$ & Слабая \\
\hline
\end{tabular}

Таблица 7.

Экспертная оценка Opportunities (Возможностей) и Threats (Угроз) СВК ОАО «РЖД»

\begin{tabular}{|l|c|}
\hline \multicolumn{1}{|c|}{ Возможности и Угрозы СВК ОАО «РЖД» } & Оценка в баллах \\
\hline \multicolumn{1}{|c|}{1} & 2 \\
\hline $0_{1}$ - возможность выступать на международной арене, предлагая свои разработки и пользуясь опытом других стран & 0,7 \\
\hline $0_{2}$ - возможность повышать свой международный рейтинг & 0,8 \\
\hline $0_{3}$ - развитие внутренней информационной и отчётной базы & 0,9 \\
\hline $\begin{array}{l}\text { O }_{4} \text { - модернизация транспортного комплекса с учетом потребностей и возможностей компании, совершенствование транспортной си- } \\
\text { стемы страны }\end{array}$ & 0,6 \\
\hline $\mathrm{T}_{1}$ - любая СВК может быть недостаточно разработана или не иметь в себе плана действий в нештатной ситуации & 0,5 \\
\hline $\mathrm{T}_{2}$ - внутренние ошибки, злоупотребления, преступления, коррупция & 0,5 \\
\hline $\mathrm{T}_{3}$ - рост конкуренции на мировом рынке, возникает риск отставания от общих тенденций, что влечет за собой снижение позиций & 0,5 \\
\hline $\mathrm{T}_{4}$ - невозможность внедрения новшеств из-за недостаточности ресурсов и из-за разной освоенности территории страны & 0,5 \\
\hline $\mathrm{T}_{5}$ - финансово-экономический кризис & 0,4 \\
\hline
\end{tabular}


Таблица 8.

Оценка коэффициентов влияния $\mathrm{d}_{\mathrm{ij}}$ Opportunities (Возможностей) и Threats (Угроз)

на Strengths (Сильные стороны) и Weaknesses (Слабые стороны) СВК ОАО «РЖД»

\begin{tabular}{|c|c|c|c|c|c|c|c|c|c|}
\hline${ }^{*} \mathbf{d}_{i j}$ & $\mathbf{0}_{\mathbf{1}}$ & $\mathbf{0}_{\mathbf{2}}$ & $\mathbf{0}_{\mathbf{3}}$ & $\mathbf{0}_{\mathbf{4}}$ & $\mathbf{T}_{\mathbf{1}}$ & $\mathbf{T}_{\mathbf{2}}$ & $\mathbf{T}_{\mathbf{3}}$ & $\mathbf{T}_{\mathbf{4}}$ & $\mathbf{T}_{\mathbf{5}}$ \\
\hline $\mathbf{S}_{\mathbf{1}}$ & 1 & 1 & 1 & 1 & 1 & 1 & 1 & 1 & 0,5 \\
\hline $\mathbf{S}_{\mathbf{2}}$ & 1 & 1 & 0,5 & 1 & 0,5 & 1 & 1 & 1 & 1 \\
\hline $\mathbf{S}_{\mathbf{3}}$ & 1 & 1 & 0,5 & 1 & 0,5 & 0,5 & 0,5 & 1 & 0,5 \\
\hline $\mathbf{S}_{\mathbf{4}}$ & 1 & 1 & 1 & 1 & 1 & 1 & 1 & 1 & 1 \\
\hline $\mathbf{S}_{\mathbf{5}}$ & 1 & 1 & 1 & 1 & 1 & 1 & 0,5 & 0,5 & 0,5 \\
\hline $\mathbf{S}_{\mathbf{6}}$ & 1 & 1 & 1 & 1 & 0,5 & 0,5 & 0,5 & 0,5 & 0,5 \\
\hline $\mathbf{S}_{\mathbf{7}}$ & 1 & 1 & 1 & 1 & 1 & 1 & 0,5 & 1 & 0,5 \\
\hline $\mathbf{W}_{\mathbf{1}}$ & 1 & 1 & 0,5 & 0,5 & 1 & 1 & 0,5 & 1 & 0,5 \\
\hline $\mathbf{W}_{\mathbf{2}}$ & 1 & 1 & 0,5 & 1 & 0,5 & 0,5 & 1 & 1 & 1 \\
\hline $\mathbf{W}_{\mathbf{3}}$ & 1 & 1 & 1 & 1 & 1 & 0,5 & 1 & 1 & 0,5 \\
\hline $\mathbf{W}_{\mathbf{4}}$ & 0,5 & 0,5 & 1 & 1 & 1 & 1 & 0,5 & 1 & 0,5 \\
\hline $\mathbf{W}_{\mathbf{5}}$ & 1 & 1 & 1 & 1 & 1 & 1 & 1 & 1 & 1 \\
\hline
\end{tabular}

рейтинге, а, значит, создает препятствия для дальнейшего прогресса и развития отрасли.

Проведем оценку Opportunities (Возможностей) и Threats (Угроз), результаты представим в Таблице 6 и Таблице 7.

Представим в Таблице 8 оценку коэффициентов $\mathrm{d}_{\mathrm{ij}}$ по степени влияния (0 - слабая степень влияния; 0,5 - средняя степень влияния; 1,0 - высокая степень влияния).

По результатам, представленным в Таблице 8 можно сделать вывод, что, при рассмотрении вопросов, связанных с внутренним контролем на ОАО «РЖД», мы не имеем значений коэффициентов влияния $\mathrm{d}_{\mathrm{ij}}$ равных нулю. Это происходит потому, что все позиции (Strengths (Сильные стороны) и Opportunities (Возможности), Strengths (Сильные стороны) и Threats (Угрозы); Weaknesses (Слабые стороны) и Opportunities (Возможности), Weaknesses (Слабые стороны) и Threats (Угрозы)) тесно взаимосвязаны, зависят друг от друга и вся текущая деятельность и вектор развития компании направлены именно на поддержание возможностей и защиту от угроз.

По данным Таблицы 8 видно, что на показатель S4 наличие кадров с высокой квалификацией, а также возможность обучать персонал корпоративной культуре, специфике работы возможности и угрозы оказывают большое влияние. Нужно сказать о важности человеческого ресурса и необходимости наличия квалифицированных кадров. Также необходимо отметить показатель W5 - большой размер задолженности оказывает прямое воздействие на финансовую структуру всей организации, так как от текущего финансового состояния и зависят наши возможности, а также распределение денеж- ных средств.

Немаловажно отметить, что в случаях ошибок мы будем вынуждены использовать временные ресурсы на их поиск, на разработку путей избегания данных денежных задержек. И, как итог, мы получим дополнительные расходы. Эта ситуация является примером, как одна ошибка, одна позиция Weaknesses (Слабых сторон) влечёт за собой дополнительные вопросы и дополнительные действия.

Таким образом, внутренний контроль представлен как система, обеспечивающая необходимой информацией аппарат управления. Также в ходе работы были выявлены методические особенности и принципов проведения внутреннего контроля дебиторской и кредиторской задолженности, дана оценка её надёжности. Данный анализ построен применительно к требованиям и потребностям осуществления процедуры внутреннего контроля на предприятиях ОАО «РЖД».

Существует два вида результативности СВК коммерческой организации:

1. Оценка количественной составляющей деятельности системы на основе расчета показателя КPI (Key Performance Indicators) - так называемый «ключевой показатель эффективности»

2. Оценка качественной составляющей деятельности системы на основе анализа статистических данных о выявленных ошибках за определенный период (существуют Ошибки 1 рода и Ошибки 2 рода).

Подробнее остановится на расчёте показателя KPI. 
KPI (Ключевой показатель эффективности) - система оценки, которая помогает организации определить достижение стратегических и операционных целей. Использование ключевых показателей результата деятельности даёт возможность предприятию оценить своё состояние и помочь в оценке реализации стратегии. Результаты KPI позволяют производить контроль деловой активности сотрудников [18], а также предоставлять результаты работы подразделений, предприятия в целом. Система KPI имеет ряд преимуществ: она прозрачна, определена и, что немало важно, нацелена именно на обратную связь «руководство - работник». В свою очередь, данная система оценки имеет недостатки: система не универсальна, а также есть зависимость материального поощрения конкретного специалиста от работы его коллег. Принимая во внимание преимущества и недостатки данной системы оценки, проанализируем четыре вагонных депо ПривДИ по данной системе оценки и посмотрим результативность системы внутреннего контроля за период с января по декабрь 2018г.

Итак, по итогам выполнения проверок, сотрудник представляет справку, в которой указывает объём проведённых проверок и количество обнаруженных ошибок. Рассчитаем систему показателей КPI (ключевые показатели эффективности) по формуле:

$$
\left(\frac{\mathrm{CM}_{\text {факт }}}{\mathrm{CM}_{\text {план }}}\right) * 100 \%
$$

где: $\mathrm{CM}_{\text {факт }}$ - фактическое количество справок о проведенных проверках;

$\mathrm{CM}_{\text {план }}$ - количество справок о проведённых проверках согласно утверждённому плану.

На эксплуатационном вагонном депо Астрахань за период с января по декабрь 2018г. фактическое количество справок о проведенных проверках составляет 5040 штук, а количество справок о проведённых проверках согласно утверждённому плану - 6200 штук.

$$
\left(\frac{5040}{6200}\right) * 100 \%=81 \%
$$

На эксплуатационном вагонном депо Максим Горький за период с января по декабрь 2018г. фактическое количество справок о проведенных проверок составляет 7440 штук, а количество справок о проведённых проверках согласно утверждённому плану - 8680 штук.

$$
\left(\frac{7440}{8680}\right) * 100 \%=86 \%
$$

На эксплуатационном вагонном депо Анисовка за период с января по декабрь 2018г. фактическое количество справок о проведенных проверок составляет 950 штук, а количество справок о проведённых проверках согласно утверждённому плану - 1100 штук.

$$
\left(\frac{950}{1100}\right) * 100 \%=86 \%
$$

На вагонном депо Аткарск за период с января по декабрь 2018г.фактическое количество справок о проведенных проверок составляет 4560 штук, а количество справок о проведённых проверках согласно утверждённому плану -4800 штук.

$$
\left(\frac{4560}{4800}\right) * 100 \%=95 \%
$$

Таким образом, по результатам работы за 2018 года по всем предприятиям выявлено, что выполнение контрольных процедур проведено не в полном объеме, это свидетельствует о возможных убытках и рисках, в связи с тем, что не все аспекты деятельности предприятий проверены и корректно отражены в регистрах бухгалтерского учета.

Итак, система показателей КРІ исследует наличие ошибок с количественной точки зрения, не классифицируя ошибки по типу, по размеру возможных штрафов или финансовых потерь. Чтобы посмотреть более подробно данные пункты, обратимся к качественной оценке составляющей системы внутреннего контроля.

Рассмотрим оценку качественной составляющей деятельности системы на основе анализа статистических данных о выявленных ошибках.

Определяют два типа ошибок: Ошибки 1 рода и Ошибки 2 рода.

Эти типы ошибок связаны с проведением выборочного контроля. Ежедневно совершается большой объём операций, и верно замечание, что проконтролировать всё практически невозможно. Поэтому введение профилактического выборочного контроля является актуальным предложением, которое может способствовать выявить ошибки. Выявление недочёта, ошибки или правонарушения влечёт за собой более полный разбор проблемы, а если ошибок по результатам выборочного контроля выявлено не было, это будет свидетельствовать о том, что в целом работа контролируемого отдела или предприятия в проверяемый период была проведена верно. Итак, рассмотрим выборочный контроль более подробно.

По результатам проведения выборочного контроля, выявленные ошибки разделяют на ошибки первого и второго рода. Ошибка первого рода не превышает уровень существенности, и система внутреннего контроля классифицирует её как нежелательную; данная ошибка может условно называться «ошибка рабочего процесса» и критерием причисления недочёта к ошибке первого рода - ошибка осуществлена в нормальную рабочую 
ситуацию. Ошибка второго рода, наоборот, превышает уровень существенности, и не обнаружена контролирующим органом вовремя. Отсюда возникает понятие риск не обнаружения ошибки, что в последующем может привести к более серьезным финансовым потерям. Таким образом, ошибка второго рода является более критичной, и поэтому более важной, по сравнению с ошибкой первого рода. Ошибками первого рода могут быть, например проводка одного документа (например, статей балансового и забалансового учёта) дважды в системе SAP R3. Необходимо вовремя исправить данную ошибку, так как в будущем она может привести к искажению отчётности. Ошибки второго рода, например, это принятие документа без отражения в учёте либо его отражение без наличия правильно оформленных первичных учётных документов. Может оказаться, что документ не соответствует условиям договора, что приведет к юридическим вопросам и финансовым потерям.

На основании анализа оценки качественной составляющей деятельности системы внутреннего контроля руководство получает информацию о среднестатистической стоимости одной ошибки, среднестатистическое количество ошибок, которые в свою очередь свидетельствуют о не результативности функционирования СBК.

\section{Далее представим расчёт данного показателя.}

В качестве ранжированной совокупности вариантов может выступить либо размер санкций за ошибку, либо размер финансовых потерь, полученных в результате ошибки;

Далее необходимо рассчитать и проанализировать основные статистические показатели:

а) Среднестатистическое арифметическое значение. Это важный показатель центра распределения ошибок, поскольку его расчет основан на учёте всех значений признака совокупности.

$$
\bar{x}=\frac{\sum x_{i} * f_{i}}{\sum f_{i}}
$$

где $x_{i}$ - варианты значений признака,

$\mathrm{f}_{\mathrm{i}}$ - частота повторений данного варианта

б) Мода. Значение элемента, встречающегося наиболее часто в ряду распределения. Моду определяем непосредственно исходя из данных.

в) Медиана. Значение признака X, которое делит общий объем совокупности пополам.

г) Размах вариации (R). Это разность между максимальным и минимальным значением признака. Данный показатель позволяет определить интервал, на котором задана статистика. Недостаток данного показателя в том, что он оценивает только заданные границы и не отражает колеблемость внутри этих границ.

$$
\mathrm{R}=\mathrm{X}_{\max }-\mathrm{X}_{\min }
$$

д) Дисперсия. Наиболее употребительная мера отклонения от среднего. Дисперсия не имеет размерности, характеризует общую вариацию признака и рассчитывается по формуле:

$$
\sigma^{2}=\frac{\sum\left(x_{i}-\bar{x}\right)^{2} * f_{i}}{\sum f_{i}} \text { средневзвешенная }
$$

е) Среднеквадратическое отклонение рассчитывается по формуле:

$$
\sigma=\sqrt{\sigma^{2}}
$$

ж) Коэффициент вариации, \%. Данный коэффициент используется для сравнения вариации разномасштабных варьирующих признаков

$$
\mathrm{V}=\left(\frac{\sigma}{\bar{x}}\right) * 100 \%
$$

Теперь рассчитаем оценку качественной составляющей деятельности системы внутреннего контроля, осуществляемой на предприятиях вагонного хозяйства ПривДИ за период - март 2019г. на основе анализа статистических данных о выявленных ошибках. Март является месяцем, закрывающим квартал, и поэтому требует особой тщательности при проверке документации перед сдачей квартальной отчётности. Итак, Приволжским ОЦОр за март 2019г. выявлены 424 ошибки. Из них 67 ошибок относится к предприятиям вагонного хозяйства ПривДИ, остальные 343 выявленные ошибки к предприятиям, бухгалтерский учет которых так же производится Приволжским ОЦОр.

Выявленные ошибки представим в Таблице 9 и для удобства расчётов поделим их на категории.

Таблица 9.

Выявленные ошибки на предприятиях вагонного хозяйства ПривДИ за март 2019г.

\begin{tabular}{|c|l|c|c|}
\hline №п\п & \multicolumn{1}{|c|}{ Категория ошибки } & $\begin{array}{c}\text { Количество } \\
\text { ошибок 1-го } \\
\text { рода }\end{array}$ & $\begin{array}{c}\text { Количество } \\
\text { ошибок 2-го } \\
\text { рода }\end{array}$ \\
\hline 1. & Техническая ошибка & 1 & 0 \\
\hline 2. & Методологическая ошибка & 7 & 1 \\
\hline 3. & Технологическая ошибка & 12 & 1 \\
\hline 4. & $\begin{array}{l}\text { Ошибка, связанная с человече- } \\
\text { ским фактором }\end{array}$ & 40 & 4 \\
\hline 5. & Ошибка третьих лиц & 1 & 0 \\
\hline
\end{tabular}


Теперь рассмотрим вопрос стоимости одной ошибки 1-го и 2-го рода.

- Стоимость технической ошибки 1-го рода - 1000 руб.; стоимость технической ошибки 2-го рода 30.000 руб.;

- Стоимость методологической ошибки 1-го рода 800 руб.; стоимость методологической ошибки 2-го рода - 35.000 руб.;

- Стоимость технологической ошибки 1-го рода 300 руб.; стоимость методологической ошибки 2-го рода - 5.000 руб.;

- Стоимость ошибки, связанной с человеческим фактором 1-го рода - 500 руб.; стоимость ошибки, связанной с человеческим фактором 2-го рода 50.000 руб.;

- Стоимость ошибки третьего лица 1-го рода - 1000 руб.; стоимость ошибки третьего лица 2-го рода 10.000 руб.

Произведём расчеты и представим результаты.

Так, рассчитаем среднестатистическое арифметическое значение:

1) $(1 * 1000)+(7 * 800)+(12 * 300)+(40 * 500)+(1 * 1000)$ $=31.200$;

2) $(0 * 30.000)+(1 * 35.000)+(1 * 5000)+(4 * 50.000)+$ $(0 * 10.000)=240.000$;

$$
\bar{x}=\frac{31.200+240.000}{67}=4.047,76
$$

Итак, среднестатистическое арифметическое значение $(\bar{x})$ равно 4.047,76 руб.

Модой в данном случае будет являться ошибка категории «Ошибка, связанная с человеческим фактором»: 40 прецедентов в Ошибках 1-го рода, и 4 Ошибки 2-го рода. В данном случае именно показатель Моды даёт нам понять, на какую категорию ошибок нужно обращать внимание в первую очередь.

Далее рассчитаем значение медианы:

1) $1000+800+300+500+1000+30000+35000+5000+500$ $00+10000=133.600$;

$$
X=133.600: 2=66.800 \text { руб. }
$$

Размах вариации равен:

$$
R=50.000-300=49.700 \text { руб. }
$$

Рассчитаем дисперсию:

$$
\begin{gathered}
\text { 1) } \begin{aligned}
&(1000-4047,76)^{2} * 1+(800-4047,76)^{2} * 7+(300-4047,76)^{2} * 12 \\
&+(500-4047,76)^{2} * 40+(1000-4047,76)^{2} * 1 \\
&+(30000-4047,76)^{2} * 0+(35000-4047,76)^{2} * 1 \\
&+(5000-4047,76)^{2} * 1+(50000-4047,76)^{2} * 4+(10000-4047,76)^{2} * 0 \\
&=10169805335,58 \\
& y^{2}=\frac{10169805335,58}{67}=151788139,33
\end{aligned}
\end{gathered}
$$

Среднеквадратическое отклонение:

$$
\mathrm{y}=\sqrt{151788139,33}=12320,23 \text { руб. }
$$

Коэффициент вариации:

$$
\mathrm{V}=\frac{12320,23}{4047,76} * 100 \%=304,37 \%
$$

Таким образом, коэффициент вариации (V) равен $304,37 \%$.

\section{ЗакАючение}

Как было отмечено раннее, коэффициент вариации (V) на основании анализа оценки качественной составляющей деятельности системы внутреннего контроля предоставляет информацию результативности (или не результативности) функционирования системы внутреннего контроля. Таким образом, если данный показатель коэффициента вариации (V) больше 100\%, можем считать данную систему неэффективной. В марте 2019 года было выявлено 424 ошибки, что достаточно много. С одной стороны, система внутреннего контроля выявила данные ошибки. С другой стороны, присутствуют Ошибки 2-го рода, что говорит о запущенности ситуации с Ошибками 1-го рода ранее.

Качественный анализ направлен на анализ грубых ошибок с целью их выявления. Данный анализ выполняется системой внешнего контроля, но, по нашему мнению, может быть внедрен и в систему внутреннего контроля организации для предупреждения и предотвращения нарушений.

\section{ЛИТЕРАТУРА}

1. Распоряжение ОАО «РЖД» от 23.01.2015 N 131р 06 утверждении Положения о системе внутреннего контроля в холдинге «РЖД» // Консультант Плюс. [Электронный ресурс] - режим доступа http://www.consultant.ru/

2. 0 направлении Методических рекомендаций по осуществлению внутреннего финансового контроля и Методических рекомендаций по осуществлению внутреннего финансового аудита [Электронный ресурс]: Письмо Министерства финансов РФ от 19.01.2015 № 02-11-05/932 // Режим доступа: http:// www.consultant.ru/document/cons_doc_LAW_122446/, свободн. - Загл. с экрана. 
3. Учётная политика ОАО «РЖД» (в редакции приказов ОАО «РЖД» от 29.12.2017 г. № 132, от 29.12.2017 г. № 133) // Режим доступа: http://doc.rzd.ru/doc/ public/ruTRUCTURE_ID=704\&layer_id=5748\&page5748_4408=11, свободный. - Загл. с экрана.

4. 06 утверждении Методических рекомендаций по построению функции внутреннего аудита в холдинговых структурах сучастием Российской Федерации [Электронный ресурс]: Приказ Росимущества от 03.09.2014 № 330 // Режим доступа: http://www.consultant.ru/document/cons_doc_LAW_168346/ , свободный. - Загл. с экрана.

5. Распоряжение от 31.10.2011г. №2338р 0б утверждении Стандарта регламентов ОАО «РЖД» // Режим доступа: http://static.scbist.com/scb/ uploaded/1_1391184556.pdf, свободный. - Загл. с экрана.

6. Бодяко А.В. Мониторинг средств внутреннего контроля экономических субъектов [Текст] / А.В. Бодяко // Вестник ИПБ (Вестник профессиональных бухгалтеров). - 2015. - № 6. - С. 3-5.

7. Бондина Н.Н. Финансовый механизм и оценка его влияния на повышениеэффективности сельскохозяйственного производства [Текст] / Н.Н. Бондина, Т.В. Зубкова, О.В. Лаврина // Известия Самарской государственной сельскохозяйственной академии. - 2014. - № 2. - С. 29-35.

8. Васильчук О.И. Построение системы внутреннего контроля экономического субъекта, направленной на обеспечение экономической безопасности [Текст] / О.И. Васильчук // Вестник СамГУПС. - 2015. - Т. 2. - № 2 (28). - С. 109 - 113.

9. Донцова Л.В. Методологические проблемы внутреннего контроля в системе международных стандартов [Текст] / Л.В. Донцова, М.М. Шарамко // Вестник Брянского государственного университета. - 2015. - № 3 (26). - С. 285-290.

10. Донцова Л.В. Методологические проблемы внутреннего контроля в системе международных стандартов [Текст] / Л.В. Донцова, М.М. Шарамко // Вестник Брянского государственного университета. - 2015. - № 3 (26). - С. 285-290.

11. Зуденкова С.А. 06 эффективности внутреннего финансового контроля [Текст] / С.А. Зуденкова, Н.В. Журавлева // Вестник университета (Государственный университет управления). - 2014. - № 21. - С. 161-163.

12. Иванов 0.Б. Практика построения риск-ориентированной системы внутреннего контроля и аудита в ОАО «Российские железные дороги» [Текст] / 0.Б. Иванов // ЭТАП: Экономическая теория, анализ, практика. - 2014. - № 4. - С. 7-31.

13. Иванов 0.Б. Риск-ориентированная система внутреннего контроля и аудита [Текст] / 0.Б. Иванов // Железнодорожный транспорт. - 2015 . - № 6. - С. $44-51$.

14. Иванов 0.Б. Состояние и направления развития систем внутреннего аудита, внутреннего контроля и управления рисками в компаниях с государственным участием [Текст] / 0.Б. Иванов, Е.А. Егорова // ЭТАП: Экономическая теория, анализ, практика. - 2015. - № 6. - С. 7-28.

15. Ивашкевич В.Б. Проблемы теории управленческого учета и контроллинга [Текст] / В.Б. Ивашкевич // Международный бухгалтерский учет. - № 7. - 2015. - C. 2-14.

16. Майсигова Л.А. Перспективы развития системы внутреннего контроля и аудита на основе риск-ориентированного подхода [Текст] / Л.А. Майсигова // Austrian Journal of Humanities and Social Sciences. - 2014. - № 9-10. - С. 306-311.

17. Рожнова О.В. Оценка эффективности СВК российских организаций в условиях кризисных экономических явлений и вступлении России в ВТО [Текст] / 0.В. Рожнова // Аудиторские ведомости. - 2015. - № 10. - С. 26-42.

18. Prokofiev S.E., Pavlyukova O.V. Building a balanced scorecard. The strategies of modern science development: proceedings of the viii international scientificpractical conference. North Charleston, SC, USA, 2015.

( ) Тарасова Татьяна Михайловна (tarasova2004@inbox.ru), Тарасова Ольга Валерьевна (tarasova-olga62@inbox.ru).

Журнал «Современная наука: актуальные проблемы теории и практики» 